\title{
EQUATIONS DESCRIBING CHANGES OF SHAPE ALONG THE FLATFISH BODY LENGTH AND THEIR IMPORTANCE FOR SUSTAINABLE AND RESPONSIBLE FISHERIES
}

\author{
Jerzy BALEJKO ${ }^{1}$, Kazimierz MILER $^{1}$, and Piotr NOWAKOWSKI ${ }^{2}$ \\ ${ }^{1}$ Division of Food Process Engineering, ${ }^{2}$ Division of Fishing Techniques; \\ Agricultural University of Szczecin, Poland
}

Balejko J., Miler K, Nowakowski P. 2007. Equations describing changes of shape along the flatfish body length and their importance for sustainable and responsible fisheries. Acta Ichthyol. Piscat. 37 (2): $113-116$.

Background. The purpose of this study was to identify mathematical equations describing changes in a flatfish body shape along its longitudinal axis. The initial function for the description of a cross-section contour is the ellipse equation including a factor deforming the symmetry with respect to one of axes. Such equations may find their use in fisheries engineering and food-fish processing.

Materials and Methods. The morphometric examination of the fish raw material was carried out in order to check whether the proposed function meets expectations and draws a curve. The model fish species used was flounder, Platichthys flesus (L.).

Results. The mathematical equation describing changes in a cross-section contour of flatfish body shape along its longitudinal axis. The high value of correlation coefficients $(r>0.99)$ showed that a hypothetical curve matches experiment results quite well. The equation describing the shape of a flatfish body cross-section contour can be defined by means of the ellipse equation including a factor deforming the symmetry with regard to one of its axes. The function represented by equation (8) draws a curve that follows the contour of the fish cross-section. Conclusion. The shape of flounder, defined in the presently reported study may have importance for sustainable and responsible fisheries, helping to design more selective fishing gear. It can also be used in food-fish engineering for designing more effective fish-processing machinery.

Keywords: fish, shape of fish, flounder, Platichthys flesus, sustainable and responsible fisheries

\section{INTRODUCTION}

According to a number of papers and manuals on fish anatomy or systematics the fish shape depends on its life style and the external environment factors (e.g., Grodziński 1971, Opuszyński 1979, Brylińska 1986). The shape of a fast-moving fish meets the requirements of the dense medium, such as water. The fusiform shape, which reduces the resistance of the medium during the motion, is the most favourable for a pelagic fish, from the point of view of hydrodynamics (Weihs 1989). The described varieties of this shape are listed in a number of ichthyology textbooks but they are characterised only in a descriptive way (Opuszyński 1979). One of the varieties of the fusiform shape is that representing of the flatfishes of the family Pleuronectidae, showing extreme lateral flattening. The information provided in the textbooks is very general and seems to be insufficient for the function-based description of the cross-section contour of the fish. Traditional morphometric papers (e.g., Wiecaszek et al. 2007) rarely describe three-dimensional aspects of fish body shape. Such fish body shape studies were prompted recently by the need to address the selectivity issue of fishing gear (Carol and García-Berthou 2007). Assuming that the fish body shape is generally fusiform (with all its varieties), we can conclude that a model representing the shape is a spheroid. The cross-section of such a solid figure is the ellipse of different degrees of eccentricity.

During model testing of tools for the fish processing, attempts of mathematical description of fish body shape were undertaken at the Faculty of Fisheries and Food Technology, Agricultural University of Szczecin (Miler et al. 1987).

A mathematical description of the cross-section contour of a fresh-water fish was published by Dowgiałło and Dutkiewicz (2002). The relation outlined by the above authors enables a quantification of the height of fish as well as its thickness in a point distant from the end of the carcass. No single equation was provided, however, to describe the shape of the whole cross-section outline in a given section of fish.

\footnotetext{
* Correspondence: Dr hab. Jerzy Balejko, prof. nadzw., Zakład Inżynierii Procesowej i Maszynoznawstwa WNoŻiR, Akademia Rolnicza w Szczecinie, ul. Papieża Pawła VI 3, 71-459 Szczecin, Poland, phone: +4891-425-0418, fax: +4891-423-1347, e-mail: zim@tz.ar.szczecin.pl
} 
A number of attempts of fish body shape description were undertaken. Suzuki and Gotoh (1982) proposed a new method of the shape analysis to characterize twodimensional forms. The Fourier coefficients are calculated for a vectorial expression of the form about the centre of gravity of 19 fish species. Loy et al. (2000) correlated the fish shape with internal anatomical data using X-rays. Characteristic shapes were associated with individual picture frames of internal anatomical anomalies. Liang at al. (1999) examined the influence of the relation between the cross-section shape of the fish body and shape of the mesh opening on fishing gear selectivity.

The fishing gear selectivity is being defined as a probability measure for catching the given fish species of the specific length and is based on the assumption, that fish escaping from the fishing gears are undamaged, minimally stressed, and would able to fully recover (Chopin and Arimoto 1995). According to Suuronen (2005) the mesh size and the shape of the net affect selective catching of the fish.

The diamond mesh changes its shape due to the forces stretching the net fabric longwise and crosswise, limiting the chances of the fish for passing through (Baranov 1960). The same diamond meshe when turned by 90 degrees of arc (Moderhak 2006) have shapes similar to cross-sections of the gadid fish. Application of the square mesh is compulsory for the trawl codends in the Baltic cod fishing (Anonymous 2005). Fuwa et al. (2003) give an example of the rectangular meshes facilitating escape of the flattened body shape fish from the fishing gear.

None of the above-mentioned papers attempted to use the cross-section contour of fish body described by mathematical equations for designing more selective fishing gear.

The shape of a flatfish seems to be particularly difficult for a description by mathematical equations, because of changing the positions of the main axes of symmetry along its body.

FUNCTIONAL DESCRIPTION OF A FISH SHAPE

The most important seems to be to use such an initial mathematical function, the graphic representation of which, would be the most approximate to a closed curve representing the fish cross-section contour and would consider changes along the fish body length.

The function that seems to describe a cross-section contour of fish is the ellipse expressed by the equation:

$$
\frac{x^{2}}{a^{2}}+\frac{y^{2}}{b^{2}}=1
$$

The next step is to identify a proper coordinate plane. Positioning axis ' $a$ ' along the longer axis of the ellipse, (Fig. 1) it is necessary to look for a deforming factor which would upset the symmetry with respect to axis ' $y$ ' and not upset the symmetry with respect to axis ' $x$ '.

The ellipse equation, where ' $a$ ' is a half of the ellipse long axis length, and ' $b$ ' is a half of the short axis, would produce:

$$
y= \pm \frac{b}{a} \cdot\left(a^{2}-x^{2}\right)^{0.5}
$$

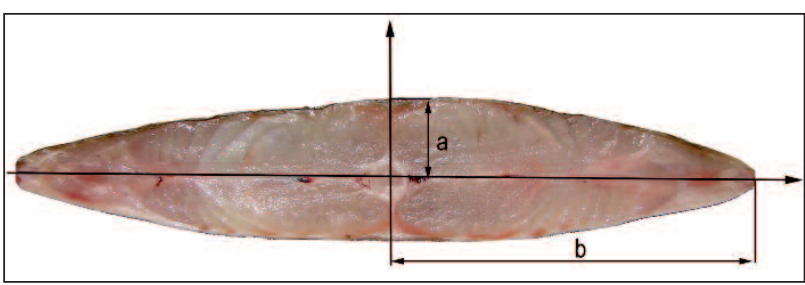

Fig. 1. Cross-section of a fish with axes of symmetry and measuring points

The deformation of the cross-section symmetry with respect to axis ' $y$ ' requires the introduction of a deforming factor to equation (2), which is a function of ' $x$ ':

$$
y \cdot G(x)= \pm \frac{b}{a} \cdot\left(a^{2}-x^{2}\right)^{0.5}
$$

where: is deforming function.

Transforming the $G(x)$ functioninto a geometric series:

$$
G(x)=1+\sum_{i=1}^{n} \gamma_{i} \cdot x^{i}
$$

Assuming that: $n=3$ and introducing expression (4) into equation (3), the function representing the location of points along the contour of the flatfish cross-section can be obtained:

$$
y= \pm \frac{b}{a} \cdot \frac{\sqrt{a^{2}-x^{2}}}{1+x \gamma_{1}+x^{2} \gamma_{2}}
$$

The constant coefficients of equation (5) have to be determined in order to verify, whether the represented function meets expectations and follows the fish crosssection contour. The morphometric study on the raw fish material was carried out to this end.

\section{MATERIALS AND METHODS}

The presently reported study was carried out on the fresh flounder, Platichthys flesus (L.), representing the autumn Baltic Sea catches and the aim of this study was to find out the suitability of equations for the description of ellipse-like cross-sections. The raw material transported in polystyrene boxes (according to Polish standards; Konarzewski et al. 1970) was delivered to the lab within 12 hours after the catch. Then, 30 fish were sampled from the entire shipment of $10 \mathrm{~kg}$ of the raw material. The fish showed no visible deformations, the average total length amounted to $29 \mathrm{~cm}$. The temperature was maintained at $2^{\circ} \mathrm{C}$ and the fish were cut into $2-\mathrm{cm}$ thick transverse sections, as shown on Fig. 2.

The measurements of the cross-sections were made by means of an image analysis method (Adesign). Each section, starting from the mouth up to the tail, was photographed in the background of the real coordinate plane.

The further geometrical analysis was completed by means of a computer method and the envelope radii were calculated using CAD software at $0,10,20,30,60,90,120$, $150,160,170$, and 180 degrees of arc counter-clockwise, 
thus obtaining 20 results for each section and 2-D coordinates for each measuring points as well.

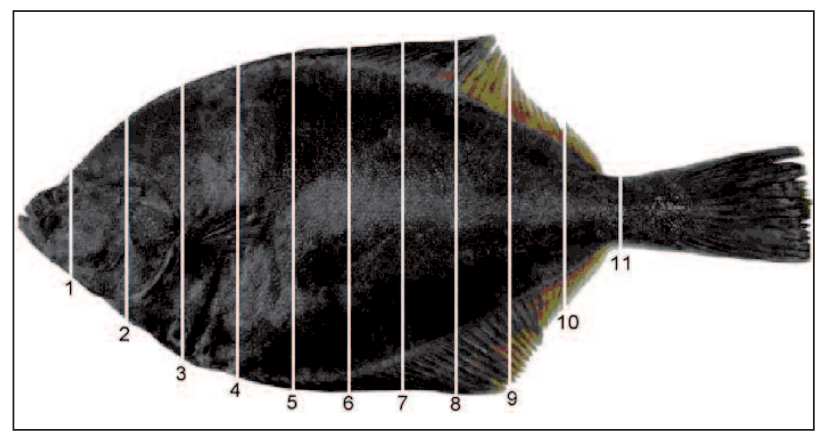

Fig. 2. The diagram of a flounder, showing consecutive cross-sections of the body

The centre of the coordinate plane was an intercept of the vertical axis of the section and its horizontal axis at half of the height. Coordinates ' $x$ ' and ' $y$ ' were calculated for points along the contour of certain fish body sections.

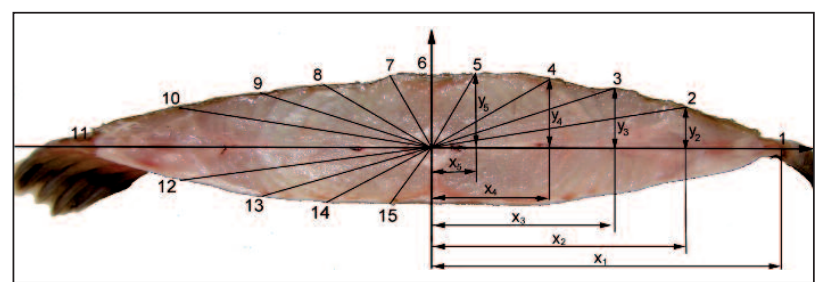

Fig. 3. Method of reading 2-D coordinates of measuring points for each cross-section

The constant coefficients of equation (5) were estimated on the basis the experimental data.

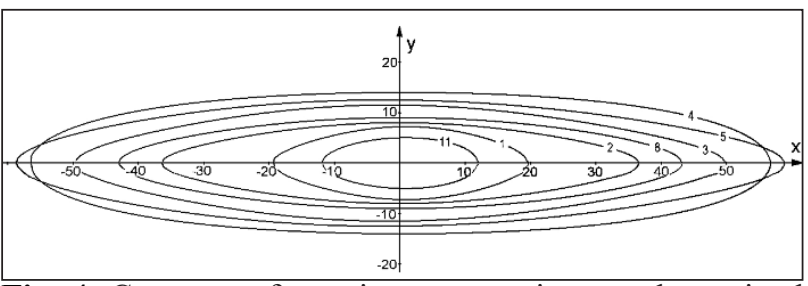

Fig. 4. Contours of certain cross-sections as determined by equation (5); numbers: $1,2,3,4,5,8$, and 11 denoting individual cross-section numbers

High values of correlation coefficients $(r>0,99)$, at size $n=600$, are very significant and show that equation (5) was correctly selected. Changes in the shape along the flat fishbody length can be described in the best way by the equation (6):

$$
\begin{gathered}
x=\lambda_{1} z^{3}+\lambda_{2} z^{2}+\lambda_{3} z+\lambda_{4} \\
x=1.49 z^{3}-9.4035 z^{2}+1.4251 z-5.5315
\end{gathered}
$$

and the graphic interpretation of the equation is a curve shown in Fig. 5.

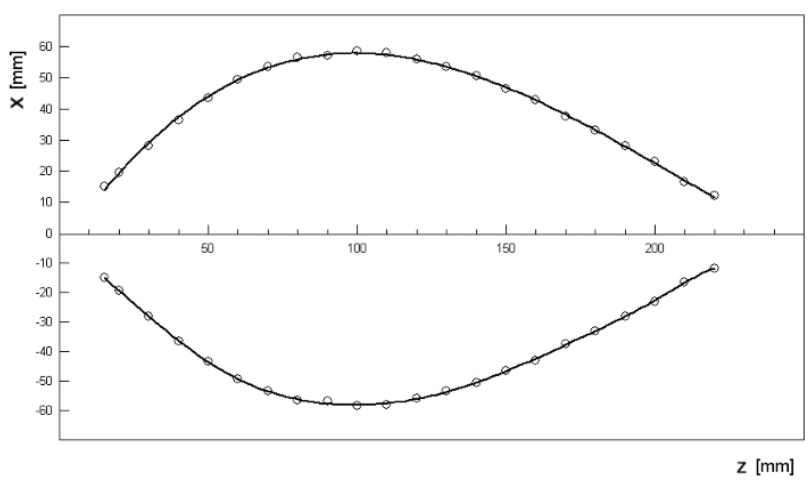

Fig. 5. Changes in longitudinal width of flatfish described by equation (6)

Values of constant coefficients of equation (5) describing the shape of the fish cross-section

Table 1 and correlation coefficient to adjust hypothetical function to experimental results

\begin{tabular}{cccrrrr}
\hline $\begin{array}{l}\text { Cross-section } \\
\text { number }\end{array}$ & $\begin{array}{c}\text { Distance from } \\
\text { head [m] }\end{array}$ & $a$ & $b$ & $\gamma_{1}$ & $\gamma_{2}$ & $r$ \\
\hline 1 & 0.02 & 7.20 & 19.615 & -0.0037 & 0.00080 & 0.999 \\
2 & 0.04 & 8.00 & 36.496 & 0.0012 & 0.00018 & 0.999 \\
3 & 0.06 & 14.00 & 49.697 & 0.0012 & 0.00018 & 0.995 \\
4 & 0.08 & 14.00 & 56.619 & -0.0001 & -0.00003 & 0.999 \\
5 & 0.10 & 12.50 & 58.730 & -0.0011 & -0.00009 & 0.990 \\
6 & 0.12 & 11.60 & 56.045 & 0.0002 & -0.00020 & 0.998 \\
7 & 0.14 & 9.50 & 50.598 & -0.0020 & -0.00006 & 0.998 \\
8 & 0.16 & 9.00 & 43.078 & -0.0001 & -0.00012 & 0.998 \\
9 & 0.18 & 8.00 & 33.028 & 0.0007 & -0.00043 & 0.998 \\
10 & 0.20 & 7.20 & 23.174 & -0.0047 & 0.00015 & 0.997 \\
11 & 0.21 & 5.00 & 11.988 & 0.0015 & -0.00499 & 0.996 \\
\hline
\end{tabular}

600 pairs of numerical data were used and regarded as the representative number of data. 
The measure of adjustment of hypothetical equation (6) to experimental values is the correlation coefficient $r=0.999$.

\section{CONCLUSION}

The equation describing the shape of a flatfish body cross-section contour can be defined by means of the ellipse equation including a factor deforming the symmetry with regard to one of its axes. The analysis of morphometric examination results leads to a conclusion that the function represented by equation (5) draws a curve that follows a contour of the fish cross-section.

The shape of flounder, defined in the presently reported study may have importance for sustainable and responsible fisheries, helping to design more selective fishing gear. It can also be used in food-fish engineering for designing more effective fish-processing machinery.

\section{REFERENCES}

Anonymous 2005. Council Regulation (EC) No 2187/2005 of 21 December for the conservation of fishery resources through technical measures in the Baltic Sea, the Belts and the Sound, amending Regulation (EC) No 1434/98 and repealing Regulation (EC) No. 88/98. Official Journal of the European Union L 349/1.

Baranov F.I. 1960. Tehnika promyšlennogo rybolovstva. [Industrial fishing techniques.] Piŝevaâ promyšlennost', Moskva. [In Russian.]

Brylińska M. (ed.) 1986. Ryby słodkowodne Polski. [The Polish freshwater fishes.] PWN, Warszawa. [In Polish.]

Carol J., García-Berthou E. 2007. Gillnet selectivity and its relationship with body shape for eight freshwater fish species. Journal of Applied Ichthyology 23: 654-660.

Chopin F.S., Arimoto T. 1995. The condition of fish escaping from fishing gears - a review. Fisheries Research 21: 315-327.

Dowgiałło A., Dutkiewicz D. 2002. Konstrukcyjne możliwości zwiększenia technologicznej wydajności operacji płatowania. [Designing potential for enhancement of the effectiveness of block filet production.] Postępy Techniki Przetwórstwa Spożywczego 2002 (1): 17-22. [In Polish.]

Fuwa S., Nakamura J., Ebata K., Kumazawa T., Hirayama M. 2003. Flow distribution on a simple separator device for trawling, TREND. Fisheries Science 69: 1169-1175.
Grodziński Z. 1971. Anatomia i Embriologia ryb. [Anatomy and embryology of fishes.] PWRiL, Warszawa. [In Polish.]

Konarzewski J., Hałubko M., Nowakowska A. 1970. Ryby i przetwory rybne, wyciągi z norm. [Fish and fish products; transcripts of standards.] Wydawnictwa Normalizacyjne, Warszawa. [In Polish.]

Liang Z., Horikawa H., Tokimura M., Tokai T. 1999. Effects of cross-sectional shape of fish body on mesh selectivity of trawl codend. Nippon Suisan Gakkaishi 65: 441-447. [In Japanese with English summary.]

Loy A., Boglione C., Gagliardi F., Ferrucci L., Cataudella S. 2000. Geometric morphometrics and internal anatomy in sea bass shape analysis (Dicentrarchus labrax L., Moronidae). Aquaculture 186: 33-44.

Miler K., Balejko J., Sznajdrowska W., Kolbiarz A. 1987. Wytyczne projektowe pilotowej linii fluidalnego wędzenia szprota. [Design specification of the pilot line for fluid smoking of sprat.] CPBR 10.11/2. [In Polish.]

Moderhak W. 2006. Turned $90^{\circ}$ netting constructions - state of the arts and facts. Pp. 109-119. In: Anonymous (ed.) Proceedings of the 7th International Workshop Methods for the Development and Evaluation of Maritime Technologies DEMaT. Korea Pukyong National University, Busan, November 23-26 2005.

Opuszyński K. 1979. Podstawy biologii ryb. [Fundamentals of fish biology.] PWRiL, Warszawa. [In Polish.]

Suuronen P. 2005. Mortality of fish escaping trawl gears. FAO Fisheries Technical Paper 478. Food and Agriculture Organization of the United Nations, Rome.

Suzuki A. Gotoh K. 1982. Two-dimensional shape analysis and its application to fish. Bulletin of the Faculty of Fisheries Hokkaido University 33: 106-114.

Weihs D. 1989. Design features and mechanics of axial locomotion in fish. American Zoologist 29: 151-160.

Więcaszek B., Krzykawski S., Antoszek A. 2007. Meristic and morphometric characters of small sandeel, Ammodytes tobianus L. (Actinopterygii: Ammodytidae), from the Gulf of Gdańsk, Baltic Sea. Acta Ichthyologica et Piscatoria 37: $37-45$.

Received: 23 May 2007

Accepted: 12 December 2007

Published electronically: 28 December 2007 